\title{
Slanted slot was the most resistant to failure of ventral slot techniques tested in rabbit cervical vertebrae
}

\author{
William McCartney ${ }^{1}$, Ciprian Ober $^{2}$, Maria J. Benito ${ }^{3}$, Brian Mac Donald ${ }^{1}$ \\ ${ }^{1}$ Dublin City University, School of Mechanical and Manufacturing Engineer, Dublin, Ireland \\ ${ }^{2}$ University of Agricultural Sciences and Veterinary Medicine, Faculty of Veterinary Medicine, \\ Department of Surgery, Cluj-Napoca, Romania \\ ${ }^{3}$ Sandyford, Dublin, Ireland
}

Received June 1, 2020

Accepted October 11, 2021

\begin{abstract}
The ventral slot technique is used to relieve neural compression secondary to intervertebral disc degeneration or disease. In the present study, the biomechanical properties of three different ventral surgical procedures in the rabbit C6-C7 vertebral motion unit (VMU) were assessed and compared with the intact C6-C7 VMU. The ventral slot procedure (slanted, full, or mini; $\mathrm{n}=8$ /group) was performed on these cervical vertebrae. Normal spine torsion and flexion values were compared to those of spines subjected to slanted, full, and mini slot surgery. The slanted slot spines were the most stable, maintaining $70 \%$ of normal cervical spine strength, compared to $26 \%$ with the full slot and $30 \%$ with the mini slot. Regarding torsion, slanted slot spines showed $74 \%$ stability compared to the normal cervical spine, while the full slot and mini slot spines showed $58 \%$ and $62 \%$ stability, respectively. Flexion values were lower after all versions of the ventral slot procedure than in the normal spine, with the greatest flexion difference occurring after the full slot procedure ( $21 \%$ of the normal flexion value). The flexion values also differed significantly between the slanted and full spine groups, and all operated spines showing roughly $60 \%$ torsion rates compared with normal spines. The slanted slot maintains more stability in rabbit cervical spine than the other procedures. To our knowledge, this was the first study to examine biomechanical failure differences between the distinct versions of this ventral slot procedure.
\end{abstract}

Biomechanical analysis, flexion, extension, torsion

Cervical intervertebral disc (IVD) disease is a common condition in veterinary medicine that causes compression of the spinal cord or nerve roots (Merbl et al. 2017). It is the most important cause of neurological deficits in dogs (Canis familiaris Linnaeus; Bray and Burbidge 1998; Sharp and Wheeler 2005), where it develops as a result of IVD degeneration following loss of functionality of the discs (Brisson 2010; Meij and Bergknut 2010; da Costa 2010). Embedded between the vertebrae, IVDs provide flexibility to the spine. They consist of the nucleus pulposus, which is the core of the IVD, surrounded by the lamellae of the annulus fibrosus and the cartilaginous endplates. Intradiscal pressure is essential for maintaining the biomechanical behaviour of the IVD. In humans, a reduction in intradiscal pressure reduces disc height, raises stress concentrations within the disc, and increases shear forces in the nucleus pulposus and annulus fibrosus upon axial compression of the spine (Hwang et al. 2012), thus enlarging the neutral zone through shear, bending, and torsion (Inoue and Espinoza 2011; Zirbel et al. 2013; Galbusera et al. 2014). The changes in bending and torsion may further increase shear stress in the nucleus. Disc degeneration is associated with changes in all these anatomical structures (Adams and Roughley 2006; Hsieh and Yoon 2010; Inoue and Espinoza 2011; Kepler et al. 2013), although the nucleus endures the most alteration (Weiler et al. 2012; I atrid is et al. 2013). Therefore, IVD degeneration or disease leads to extrusion or protrusion of disc material into the vertebral canal, resulting in neural tissue compression or concussion that then manifests clinical signs. 
The IVD plays a key role in the posture and movement of the spine; it facilitates load transfer and guides vertebral movement (Jaumard et al. 2011). IVD failure causes disorders such as cervical and thoracolumbar IVD herniation (Hansen 1952). Other diseases caused by IVD degeneration, such as cervical spondylomyelopathy (da Costa et al. 2006a) manifest the clinical signs of spinal cord or nerve root compression, including neurological deficits and cervical hyperesthesia (da Costa et al. 2006b). Numerous changes in disc morphology and physiology have been described. In the development of IVD, a significant role is played by the order and causal relationships of the biological and biomechanical alterations (Hsieh and Yoon 2010; Chan et al. 2011), which can be caused by biomechanical wear and tear (Adams et al. 2015), mechanical disturbances to cellular physiology (Boubriak et al. 2013), or pathogens (Alpantaki et al. 2011).

Cervical IVD herniation with associated spinal cord injury is a common condition in dogs (Brisson 2010; Bergknut et al. 2013). Large-breed dogs such as Labrador Retrievers, Dalmatians, Weimaraners, German Shepherds, Rottweilers, and Doberman Pinschers can be particularly affected by cervical disc extrusions, accounting for up to $24 \%$ of all cases (Cherrone et al. 2004; Forterre et al. 2008; Ryan et al. 2008), although a disc extrusion can occur in any breed (Gough et al. 2018). When large-breed dogs are affected by acute or chronic cervical disc disease, an underlying malformation or instability might be present, such as cervical spondylomyelopathy disorder (da Costa 2010; Platt and da Costa, 2011; De Decker et al. 2012). In large breed dogs, disc extrusions are more common in the lower cervical vertebral column, specifically C5-C6 and C6-C7 (Longshore 2009).

Surgical exploration of cervical disc extrusions and spinal decompression has been accomplished using various procedures, including disc fenestration, ventral slot, dorsal laminectomy, hemilaminectomy, and slanted slot (Wheeler and Sharp 2005; McCartney 2007). The ventral approach has several advantages in that it requires minimal muscle dissection and allows prophylactic fenestration of adjacent cervical discs. The conventional ventral slot procedure is the most commonly performed surgical treatment for decompression of the spinal cord following cervical intervertebral disc herniation (Chambers et al. 1982; Fauber et al. 2006). Variations of this procedure include the inverted cone technique, which is a modification of the traditional ventral slot method aimed at minimizing bone removal and thus reducing the risk of vertebral subluxation. Meanwhile, the slanted slot technique removes only the caudal aspect of the cranial vertebral body to access the extruded disc material (da Costa 2017). Ventral slots alter the vertebral range of motion at the surgical site, which can lead to instability and subluxation (da Costa 2017). Indeed, the procedure involves removing the dorsal and ventral portions of the annulus fibrosus of the disc, the nucleus pulposus, and the longitudinal vertebral ligaments, and it creates a bone defect in the adjoining vertebral bodies. As such, it can lead to postsurgical instability, vertebral collapse, and subluxation (Macy et al. 1999; Fitch et al. 2000; Lemarie et al. 2000). The slanted ventral slot procedure allows access to the dorsal anulus fibrosus, vertebral end plate, and ventral spinal canal for decompression of the spinal cord after herniated IVD, while maintaining the integrity of the ventral anulus fibrosus (McCartney 2007). It provides access to the vertebral canal at the site of IVD herniation without removing a large portion of the annulus fibrosus, thereby potentially preserving more stability at the surgical site than the standard ventral slot technique (McCartney 2007).

Mechanical models of disc degeneration can be broadly divided into compression and instability models (Lotz 2004; Daly et al. 2016). In the present study, a laboratory analysis was carried out using the cervical vertebrae of the rabbit (Oryctulagus cuniculus Linnaeus) to compare normal spines with the three ventral slot approaches: slanted, mini, and full. To our knowledge, this was the first study to examine the differences in biomechanical failure between the distinct versions of the ventral slot procedure. These three techniques must be evaluated further to provide information that is relevant to clinical cases. 


\section{Ethics \\ Materials and Methods}

The animals were sourced from an authorized breeder and were humanely euthanized at slaughter for human consumption. All procedures performed in the present study followed the guidelines of Directive 2010/63/EU, as well as the national legislation (Law No. 43/2014). The project was carried out in the Faculty of Veterinary Medicine and was approved by the Committee for Bioethics and Research Ethics (Accord No. 77/2017)

Animals

The cervical and thoracic spines of forty Lionhead rabbits of similar age (3 months) and size (median weight: $2 \mathrm{lbs}$ ), destinated for human consumption, were removed up to the level of T5. Before use in the experiment, the spines were radiographed to ensure they were intact. Any spine that was damaged during removal was excluded from the study. The undamaged cervical spines were then split into four groups: untreated control, full ventral slot procedure, mini ventral slot procedure, and slanted ventral slot procedure (Plate V, Fig. 1). The samples were frozen until the testing conditions were prepared. After defrosting, the full ventral slot, slanted ventral slot, or mini ventral slot procedures were performed at the $\mathrm{C} 6-\mathrm{C} 7$ vertebrae. During these procedures, the spines were maintained at $4{ }^{\circ} \mathrm{C}$. The slot size was calculated in accordance with guidelines and recommended limits in the literature (Chambers et al. 1982). A mini slot was defined as 50\% of a full slot. This procedure was chosen for testing purposes to represent grading of bone removal. That is, mini slot surgery is never carried out in practice; instead, this category was used to chart the differences between the slanted and full slots by creating an intermediary class.

Immediately after surgery, all samples underwent biomechanical analysis. For this purpose, the samples were embedded in a custom holder and inserted into grips (Plate V, Fig. 2). They were then positioned in the testing jig and minimally preloaded to ensure the correct loading and spine position was used - that is, to ensure that the spines were loaded in flexion rather than extension. For biomechanical testing, the crosshead speed was set at $1.5 \mathrm{~mm} / \mathrm{s}$, and failure was noted as a fracture of the vertebrae. Five specimens from each group were evaluated for failure in flexion and torsion in the testing equipment.

\section{Statistical analysis}

The two variable outcomes-flexion and torsion-were measured multiple times in one spine sample. To account for the impact of displacement upon outcomes, the comparison of spines was paired. That is, for each spine, a measurement at a specific displacement was paired with another measurement at the same distance in another spine.

The experimental spines to undergo slanted slot, full slot, and mini slot surgery were compared with control spines using the Wilcoxon matched-pairs test. Additional comparisons were performed between slanted and full slot spines.

Mixed-effects models were implemented using commercially available software (IBM SPSS Statistics Version 23; International Business Machines Corp., Armonk, NY, USA). Results were considered significant at $P$ values $<0.05$.

\section{Results}

Ultimately, forty spines were used for testing. The average length of these spines was $6.5 \mathrm{~cm}$, while the average width was $1 \mathrm{~cm}$, with little variation in size between the samples. Four rabbit spines collected and radiographed were rejected due to damage during the collection process, while another six were rejected following thawing due to damage detected upon removal for thawing. Two further spines were discarded due to damage incurred during the initial set-up of the testing apparatus.

\section{Failure point in flexion and torsion}

In the case of torsion, the average failure points at $35 \mathrm{Nmm}^{2}$ in the four experimental groups were as follows: $1.059^{\circ}$ in normal control spines, $0.792^{\circ}$ in the slanted slot group, $0.659^{\circ}$ in the mini slot group, and $0.615^{\circ}$ in the full slot group, as represented in the graph in Fig. 3 (Plate VI). The torsion tests were stopped at sample failure, as determined by audible fracture. The graph in Fig. 4 (Plate VI) shows that the average failure points of the spines in flexion were: $30 \mathrm{Nmm}$ in normal control spines, $21.6 \mathrm{Nmm}$ in the slanted slot group, $9 \mathrm{Nmm}$ in the mini slot group, and $8 \mathrm{Nmm}$ in the full slot group, as determined when obvious fractures occurred.

\section{Statistical results of the flexion point analysis}

The comparisons between normal control spines and each of the other groups of spines are summarized in Table 1. In each experimental group, the flexion values were significantly 
lower than in the normal spines, with the lowest value occurring in the full slot group (13.3 vs. 2.0), followed by the mini slot group (5.3). In contrast, the slanted slot spines displayed a relatively elevated plateau near the failure point $(9.0)$. The largest difference in flexion point from the normal control group occurred in the full slot group, in which the median flexion point was roughly five times lower than that of the control spines: only $21 \%$. All experimental groups - full, mini, and slanted slot-showed significantly lower flexion points than the control spines $(P<0.001$ in all cases). An additional comparison revealed that the flexion points of the slanted slot spines were significantly higher than those of the full slot spines (Plate VI, Fig. 4).

Table 1. Flexion points in normal spines and in spines that have underwent full, slanted, or mini ventral slot surgery. The first column represents the median and inter-quartile range (IQR) flexion values of each group. For each individual measurement, the relative difference in flexion between each spine and the equivalent point in the normal spine was calculated. A significant difference was found between each group and the control spine group $(P<0.001$ in each case $)$.

\begin{tabular}{lccc}
\hline Spine & Flexion median $(\mathrm{IQR})$ & Relative difference to normal median $(\mathrm{IQR})$ & $P$ value $($ vs. normal) \\
\hline Normal & $13.3(6.0,22.7)$ & - & - \\
Full & $2.0(1.3,4.6)$ & $0.21(0.18,0.25)$ & $<0.001^{*}$ \\
Slanted & $9.0(3.0,14.0)$ & $0.90(0.64,0.95)$ & $<0.001^{*}$ \\
Mini & $5.3(2.7,7.3)$ & $0.42(0.36,0.46)$ & $<0.001^{*}$ \\
\hline
\end{tabular}

Statistical results of the torsion test

A similar set of analyses was performed to compare the torsion values among the four groups of spines (Table 2). Firstly, the control group was compared with each experimental spine group. Torsion values were significantly lower in the full slot and mini slot spine groups than in normal spines (controls: 0.54 , full slot: 0.34 , mini slot: $0.38 ; P<0.05$ in both cases; Plate VI, Fig. 3). In both groups, the values were roughly $60 \%$ of those in the normal control spines. The torsion of the slanted slot spines was also lower than that of the control spines, but not significantly so.

A further comparison between the slanted slot and full slot groups showed significantly lower torsion values in the full slot group than in the slanted slot group $(P=0.02)$.

Table 2. Torsion values in normal spines and in spines that have undergone full, slanted, or mini ventral slot surgery. Data expressed as median and range, with the data range representing the spread of values. Both the full slot and mini slot groups showed significant difference from the control spine group $(P<0.05$ in both cases), whereas the slanted slot group did not.

\begin{tabular}{lccc}
\hline Spine & Torsion median (range) & Relative difference to normal median (range) & $P$ value (vs. normal) \\
\hline Normal & $0.54(0.17,1.06)$ & - & - \\
Full & $0.34(0.06,0.62)$ & $0.58(0.39,0.64)$ & $0.02 *$ \\
Slanted & $0.49(0.19,0.79)$ & $0.84(0.70,1.13)$ & 0.06 \\
Mini & $0.38(0.07,0.66)$ & $0.62(0.37,0.73)$ & $0.02 *$ \\
\hline
\end{tabular}

\section{Discussion}

The present study sought to compare the biomechanical behaviour at the C6-C7 cervical vertebrae in normal rabbit spines with that in spines subjected to the slanted slot, full ventral slot, and mini ventral slot procedures. The cervical spines in the slanted slot group maintained significantly more strength than those in either the full or mini ventral slots.

The slanted ventral slot procedure was first used in the literature by Slocum and Devine-Slocum (1998) to treat cervical disc disease and avoid undue weakening of the cervical vertebral motion unit (VMU). Vertebral collapse is a recognized complication of the standard ventral slot procedure. 
In clinical cases, full slot procedures have a higher complication rate than modified slanted slot procedures. McCartney (2007) showed that ventral decompression using the modified slanted slot instead of the standard ventral slot allowed for spinal decompression with potentially less destabilization, and that the rate of complications was higher in the full slot group. Dogs with IVD protrusions between C2 and C4 responded favourably to ventral slot decompression, while those with protrusions between $\mathrm{C} 4$ and $\mathrm{C} 7$ showed poorer response to this technique, displaying more severe clinical effects on motor function, recovery, and long-term outcome after surgery (Fitch et al. 2000). Other studies involving disc fenestration and ventral slots in the C5-C6 VMU in dogs (Lemarie et al. 2000; Fauber 2006) have found that this procedure affects the biomechanics of the vertebrae by causing vertebral subluxation, suggesting that wide ventral slots may contribute to postoperative instability of the vertebrae. Recently, Merbl et al. (2017) reported that triple ventral slot decompression surgery can be applied in small-breed dogs with multiple disc herniations from $\mathrm{C} 3$ to $\mathrm{C} 6$.

In the present study, laboratory analysis of rabbit cervical vertebrae revealed that the slanted slot conferred greater flexion stability than the full slot, showing $26 \%$ lower stability than normal spines, compared to the $42 \%$ lower stability conferred by the full slot. In the torsion test, the full slot and the slanted slot spines were $44 \%$ and $34 \%$ less stiff than the normal spines, respectively. Although the experiment was performed on rabbit spines, this result is particularly relevant given that the caudal canine cervical spine shows greater torsion. However, no data are available regarding rabbit spine biomechanics to draw concrete comparisons between dog and rabbit.

Yang et al. (2016) found no significant difference in biomechanical response between the slanted and full-size slots in the C5-C6 space of dog spinal specimens, probably because both methods disrupt the nucleus pulposus and dorsal annulus fibrosus of the disc. However, we cannot compare our results to these previous studies because we investigated a different slot (C6-C7), used a spinal column of different length, and applied different mechanical analysis. Furthermore, in the present study, we used rabbit spines, which have different properties from dog spines.

The rabbit model of IVD degeneration has been utilized by several authors to investigate disc degeneration and potential therapeutic agents (Masuda et al. 2005; Miyamoto et al. 2010). Masuda et al. (2005) found that using rabbit spines to investigate disc disease was acceptable and reproducible. Grauer et al. (2000) found that rabbit spines had similarities to human spine, but that they showed greater laxity.

The biomechanical testing in the present study showed that the slanted slot procedure preserves some mechanical aspects of the cervical vertebrae in rabbits better than the full ventral slot procedure. However, this model may not accurately reflect dynamic behaviours that occur in living patients, wherein soft tissues are preserved and multiplanar motion takes place. In this regard, the model is similar to other relevant ex vivo biomechanical models of the cervical vertebral column (Koehler et al. 2005; Fauber 2006; Adamo et al. 2007; Yang et al. 2016). For this reason, the findings of the present study may not translate directly into the clinical situation.

The samples in the present study were more uniform than those of previous studies. Furthermore, we tested the samples until the point of failure. For these reasons, further research should be conducted to corroborate the current results. Testing to failure is unconventional in spinal biomechanics studies. However, we deemed it most appropriate in the present study because only a small number of samples were used, and because we wished to examine the vertebral collapse scenario specifically. Nonetheless, this decision to apply testing to failure was a significant limiting factor in the present study. Interestingly, as depicted in the force deformation curve, all tested samples in the present study shared a short period during which the gradient of their respective curves was similar, followed 
by divergence as greater force was applied. This may partly explain why other studies have found similar results for various methods of ventral decompression. However, as we were examining the vertebral collapse scenario, it was necessary to extend the loading to failure.

This was the first study to confirm in a laboratory analysis that the slanted slot is more stable than a standard ventral slot, albeit in a failure setting. Hermann et al. (2018) evaluated four different ventral surgical procedures of the cervical vertebrae in dogs' spines, with results that contradicted the present study. Similar biomechanical effects of the slot techniques were detected, but the slanted slot did not provide any biomechanical benefit. However, that study only applied load within a short range, not to failure, so it may not have shown the full biomechanical behaviour of the spines.

The major limitation of this study was the extrapolation of data from rabbit spines to dogs. Although rabbits are commonly used as an animal model to study biological and biochemical processes related to spinal cord injury and recovery, they have different anatomical structures and morphology and do not naturally suffer from cervical instability or IVD degeneration. Unsuccessful outcomes, such as subluxations, collapsed disc space, and long-term degenerative changes in adjacent disc spaces (known as domino effect) were not the focus of this ex vivo biomechanical study, especially because the two species have such different anatomical structures and morphology.

Additionally, the small size of rabbit cervical spines created difficulties in handling and testing. Only flexion and torsion were chosen for testing because we needed enough samples to perform statistical analysis and these parameters are the most significant when examining the different ventral slot techniques. Failure of the procedure was considered when the vertebrae fractured, which hardly ever occurs under clinical conditions in dogs. However, we defined vertebral fracture as the failure point to test the model to the extreme and elucidate the full behaviour of the model.

Overall, the present study revealed that the slanted slot maintains significantly more stability in the cervical spine than either the full or mini ventral slot when tested to failure, suggesting that this modality is superior to the conventional ventral slot procedure. Thus, the present study buttresses the notion that the slanted slot confers a decreased incidence of vertebral collapse in a clinical setting. Further clinical studies are needed to evaluate the use of slanted slot in dogs and to assess its effect in the most common and challenging post-operative complications of ventral slots in dogs.

\section{Acknowledgements}

This project was funded by the Ministry of Research and Innovation through Program 1- Development of the National Research and Development System, Subprogram 1.2- Institutional performance - Projects for Financing the Excellence in CDI, Contract no 37PFE/06.11.2018. Title of the project: Increasing the institutional performance through consolidation and development of research directions within the USAMVCN.

\section{References}

Adamo PF, Kobayashi H, Markel M, Vanderby R 2007: In vitro biomechanical comparison of cervical disk arthroplasty, ventral slot procedure, and smooth pins with polymethyl-methacrylate fixation at treated and adjacent canine cervical motion units. Vet Surg 36: 729-741

Adams MA, Roughley PJ 2006: What is intervertebral disc degeneration, and what causes it? Spine 31: 2151-2161

Adams MA, Lama P, Zehra U, Dolan P 2015: Why do some intervertebral discs degenerate, when others (in the same spine) do not? Clin Anat 28: 195-204

Alpantaki K, Katonis P, Hadjipavlou AG, Spandidos DA, Sourvinos G 2011: Herpes virus infection can cause intervertebral disc degeneration: A causal relationship? J Bone Joint Surg Br 93: 1253-1258

Bergknut N, Smolders LA, Grinwis GC, Hagman R, Lagerstedt AS, Hazewinkel HAW, Tryfonidou MA, Meij BP 2013: Intervertebral disc degeneration in the dog. Part 1: Anatomy and physiology of the intervertebral disc and characteristics of intervertebral disc degeneration. Vet J 195: 282-291 
Boubriak OA, Watson N, Sivan SS, Stubbens N, Urban JPG 2013: Factors regulating viable cell density in the intervertebral disc: Blood supply in relation to disc height. J Anat 222: 341-348

Brisson BA 2010: Intervertebral disc disease in dogs. Vet Clin North Am Small Anim Pract 40: 829-858

Bray JP, Burbidge HM 1998: The canine intervertebral disk: part one: structure and function. J Am Anim Hosp Assoc 34: 55-63

Chambers JN, Oliver JE Jr, Kornegay JN, Malnati GA 1982: Ventral decompression for caudal cervical disk herniation in large- and giant-breed dogs. J Am Vet Med Assoc 180: 410-414

Chan SCW, Ferguson SJ, Gantenbein-Ritter B 2011: The effects of dynamic loading on the intervertebral disc. Eur Spine J 20: 1796-1812

Cherrone KL, Dewey CW, Coates JR, Bergman RL 2004: A retrospective comparison of cervical intervertebral disk disease in nonchondrodystrophic large dogs versus small dogs. J Am Anim Hosp Assoc 40: 316-320

da Costa RC 2010: Cervical spondylomyelopathy (wobbler syndrome) in dogs. Vet Clin North Am Small Anim Pract 40: 881-913

da Costa RC, Parent JM, Partlow G, Dobson H, Holmberg DL, Lamarre J 2006a: Morphologic and morphometric magnetic resonance imaging features of Doberman Pinschers with and without clinical signs of cervical spondylomyelopathy. Am J Vet Res 67: 1601-1612

da Costa RC, Poma R, Parent JM, Partlow G, Monteith G 2006b: Correlation of motor evoked potentials with magnetic resonance imaging and neurologic findings in Doberman Pinschers with and without signs of cervical spondylomyelopathy. Am J Vet Res 67: 1613-1620

da Costa RC 2017: Ventral cervical decompression. In: Shores A, Brisson BA (Eds): Current Techniques in Canine and Feline Neurosurgery. Town, Wiley Blackwell, $157 \mathrm{p}$.

Daly C, Ghosh P, Jenkin G, Oehme D, Goldschlager T 2016: A review of animal models of intervertebral disc degeneration: Pathophysiology, regeneration, and translation to the clinic. Biomed Res Int 2016: 5952165

De Decker S, da Costa RC, Volk HA, Van Ham LML 2012: Current insights and controversies in the pathogenesis and diagnosis of disc-associated cervical spondylomyelopathy in dogs. Vet Rec 171: 531-537

Fauber AE, Wade JA, Lipka AE, McCabe GP, Aper RL 2006: Effect of width of disk fenestration and a ventral slot on biomechanics of the canine C5-C6 vertebral motion unit. Am J Vet Res 67: 1844-1848

Fitch RB, Kerwin SC, Hosgood G 2000: Caudal cervical intervertebral disk disease in the small dog: Role of distraction and stabilization in ventral slot decompression. J Am Anim Hosp Assoc 36: 68-74

Forterre F, Konar M, Tomek A, Doherr M, Howard J, Spreng D, Vandevelde M, Jaggy A 2008: Accuracy of the withdrawal reflex for localization of the site of cervical disk herniation in dogs: 35 cases (2004-2007). J Am Vet Med Assoc 232: 559

Galbusera F, van Rijsbergen M, Ito K, Huyghe JM, Brayda-Bruno M, Wilke HJ 2014: Ageing and degenerative changes of the intervertebral disc and their impact on spinal flexibility. Eur Spine J 23: S324-S332

Gough A, Thomas A, O’Neill D 2018: Dogs Breed 2018. Breed Predispositions to Disease in Dogs and Cats. $3^{\text {rd }}$ edn. Wiley-Blackwell, $416 \mathrm{p}$.

Grauer JN, Erulkar JS, Patel TC, Panjabi MM 2000: Biomechanical evaluation of the New Zealand white rabbit lumbar spine: a physiologic characterization. Eur Spine J 9: 250-255

Hansen HJ 1952: A pathologic-anatomical study on disc degeneration in dog, with special reference to the so-called enchondrosis intervertebralis. Acta Orthop Scand Suppl 11: 1-117

Hermann A, Voumard B, Waschk MA, Hettlich BF, Forterre F 2018: In vitro biomechanical comparison of four different ventral surgical procedures on the canine fourth-fifth cervical vertebral motion unit. Vet Comp Orthop Traumatol 31: 413-421

Hsieh AH, Yoon ST 2010: Update on the pathophysiology of degenerative disc disease and new developments in treatment strategies. Open Access J Sports Med 1: 191-199

Hwang D, Gabai AS, Yu M, Yew AG, Hiseh AH 2012: Role of load history in intervertebral disc mechanics and intradiscal pressure generation. Biomech Model Mechanobiol 11: 95-106

Iatridis JC, Nicoll SB, Michalek AJ, Walter BA, Gupta MS 2013: Role of biomechanics in intervertebral disc degeneration and regenerative therapies: what needs repairing in the disc and what are promising biomaterials for its repair? Spine J 13: 243-262

Inoue N, Espinoza Orías AA 2011: Biomechanics of intervertebral disk degeneration. Orthop Clin North Am 42: 487-499

Jaumard NV, Welch WC, Winkelstein BA 2011: Spinal facet joint biomechanics and mechanotransduction in normal, injury and degenerative conditions. J Biomech Eng 133: 071010

Kepler CK, Ponnappan RK, Tannoury CA, Risbud MV, Anderson DG 2013: The molecular basis of intervertebral disc degeneration. Spine J 13: 318-330

Koehler CL, Stover SM, LeCouteur RA, Schulz KS, Hawkins DA 2005: Effect of a ventral slot procedure and of smooth or positive-profile threaded pins with polymethylmethacrylate fixation on intervertebral biomechanics at treated and adjacent canine cervical vertebral motion units. Am J Vet Res 66: 678-687

Lemarie RJ, Kerwin SC, Partington BP, Hosgood G 2000: Vertebral subluxation following ventral cervical decompression in the dog. J Am Anim Hosp Assoc 36: 348-358

Longshore RC 2009: Cervical disorders of large breed dogs. CVC in San Diego Proceedings 
Lotz JC 2004: Animal models of intervertebral disc degeneration: Lessons learned. Spine 29: 2742-2750

Macy NB, Les CM, Stover SM, Kaas PH 1999: Effect of disk fenestration on sagittal kinematics of the canine C5-C6 intervertebral space. Vet Surg 28: 171-179

Masuda K, Aota Y, Muehleman C, Imai Y, Okuma M, Thonar EJ, Andersson GB, An HS 2005: A novel rabbit model of mild, reproducible disc degeneration by an anulus needle puncture: Correlation between the degree of disc injury and radiological and histological appearances of disc degeneration. Spine 30: 5-14

McCartney W 2007: Comparison of recovery times and complication rates between a modified slanted slot and the standard ventral slot for the treatment of cervical disc disease in 20 dogs. J Small Anim Pract 48: 498-501

Meij BP, Bergknut N 2010: Degenerative lumbosacral stenosis in dogs. Vet Clin North Am Small Anim 40: 983-1009

Merbl Y, Shamir MH, Chamisha Y, Peery D 2017: Three consecutive ventral slots for the treatment of cervical intervertebral disk disease in a dog. Isr J Vet Med 72: 49-53

Miyamoto T, Muneta T, Tabuchi T, Matsumoto K, Saito H, Tsuji K, Sekiya I 2010: Intradiscal transplantation of synovial mesenchymal stem cells prevents intervertebral disc degeneration through suppression of matrix metalloproteinase-related genes in nucleus pulposus cells in rabbits. Arthritis Res Ther 12: R206

Platt SR, da Costa RC 2011: Cervical spine. In: Tobias K, Johnston S (Eds): Veterinary Surgery: Small Animal. $1^{\text {st }}$ edn. WB Saunders, Philadelphia, $430 \mathrm{p}$.

Ryan TM, Platt SR, Llabres-Diaz FJ, McConnell JF, Adams VJ 2008: Detection of spinal cord compression in dogs with cervical intervertebral disc disease by magnetic resonance imaging. Vet Rec 163: 11

Sharp NJH, Wheeler SJ 2005: Thoracolumbar and lumbosacral disease. In: Sharp NJH, Wheeler SJ (Eds): Small Animal Spinal Disorders. Diagnosis and Surgery. $2^{\text {nd }}$ edn. Elsevier, Mosby, Edinburgh, UK, pp. 121-209

Slocum B, Devine-Slocum T 1998: Slanted slot for cervical decompression. In: Bojrab MJ, Ellison GW, Slocum B (Eds): Current Techniques in Small Animal Surgery. $4^{\text {th }}$ edn. William \& Wilkins, Philadelphia, PA, USA, pp. $826-828$

Weiler C, Schietzsch M, Kirchner T, Nerlich AG, Wuertz K 2012: Age-related changes in human cervical, thoracal and lumbar intervertebral disc exhibit a strong intra-individual correlation. Eur Spine J 21: S810-S818

Wheeler SJ, Sharp JH 2005: Cervical disc disease. In: Wheeler SJ, Sharp JH (Eds): Small Animal Spinal Disorders: Diagnosis and Surgery. $2^{\text {nd }}$ edn. Elsevier, Mosby, Edinburgh, UK, pp. 92-120

Yang H, Lambrechts NE, Lehner M, Adam GM, Packer RA, Moore TW, Main RP 2016: Effects of conventional and slanted ventral slot procedures on the biomechanical behavior of the C5-C6 vertebral motion unit in dogs. Am J Vet Res 77: 846-853

Zirbel SA, Stolworthy DK, Howell LL, Bowden AE 2013: Intervertebral disc degeneration alters lumbar spine segmental stiffness in all modes of loading under a compressive follower load. Spine J 13: 1134-1147 
Plate V

McCartney W. et al.: Slanted ... pp. 043-050

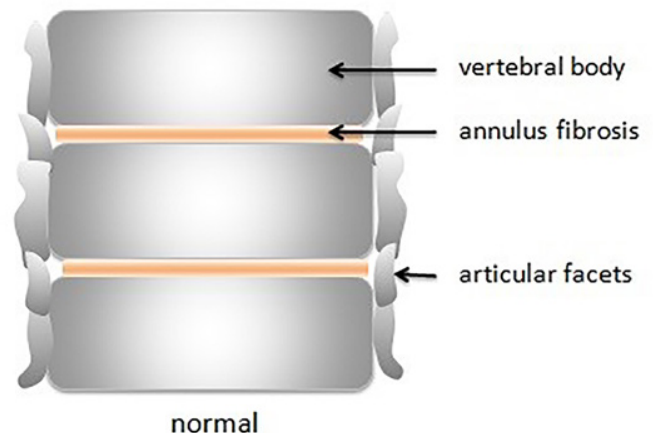

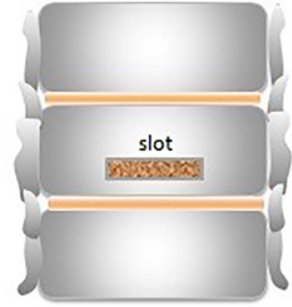

Slanted slot

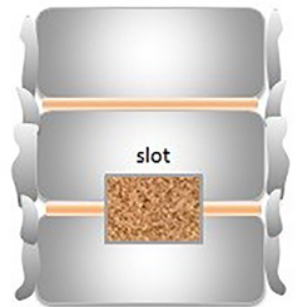

Full slot

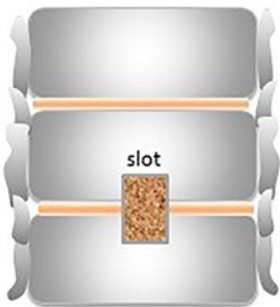

Mini slot

Fig. 1. Simple diagrams outlining the salient differences between the three procedures

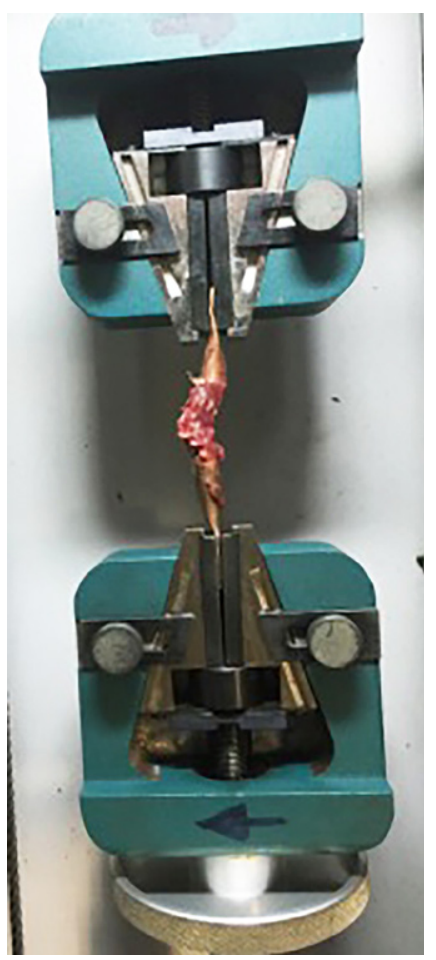

Fig. 2. Photograph of the testing set-up 


\section{Torsion data}

1.2

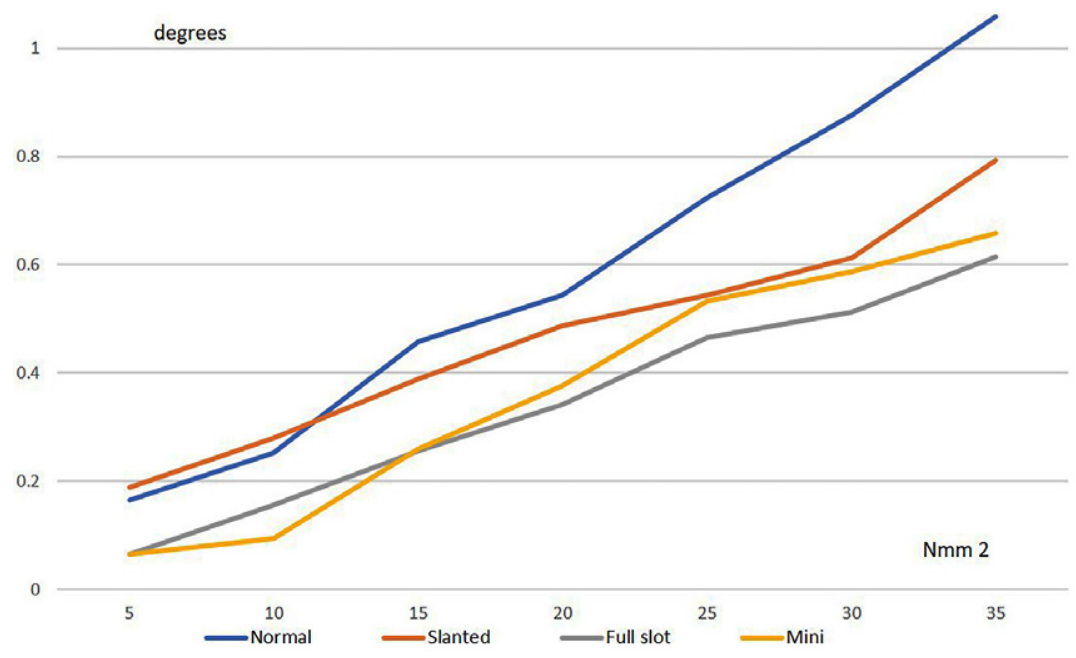

Fig. 3. Graph shows rabbit cervical spine failure under torsional loads. The blue line represents normal spines, the orange line the slanted slot group, the grey line the full slot group, and the yellow line the mini slot group. The $\mathrm{Y}$ axis represents degrees; torsional force in the $\mathrm{X}$ axis is shown in $\mathrm{Nmm} 2$.

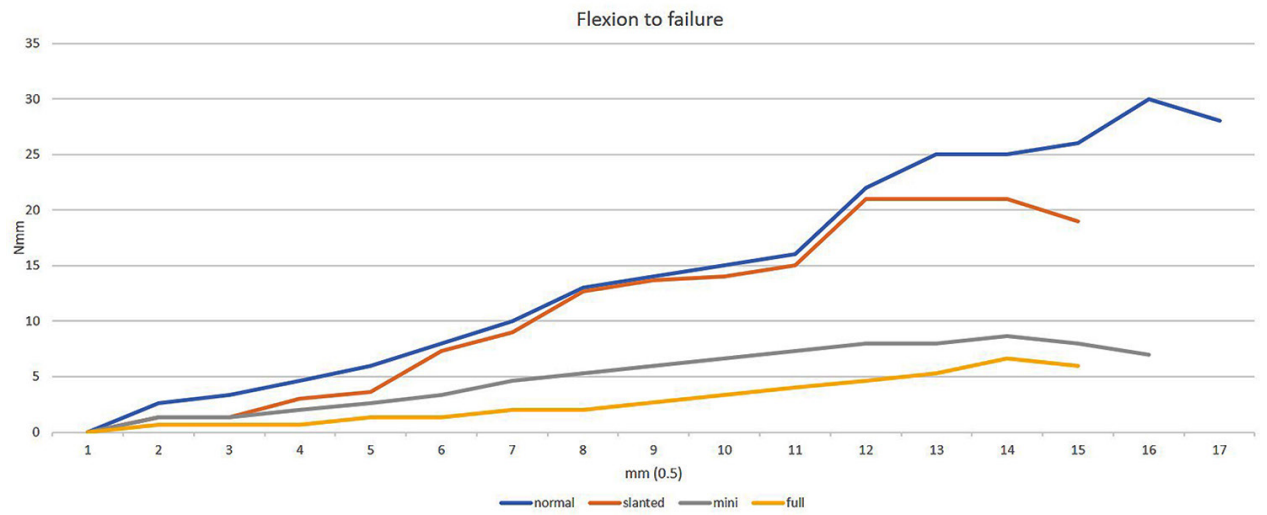

Fig. 4. Graph showing the flexion to failure results comparing the different methods. The grey line represents normal spines, the orange line the full slot group, the yellow line the slanted slot group, and blue line the mini slot group. The $\mathrm{Y}$ axis represents momentum, expressed in $\mathrm{Nmm}$; length in the $\mathrm{X}$ axis is given in $\mathrm{mm}$. 